\title{
Splenic injury following Colonoscopy
}

\author{
Paheerathan N, Branavan S \\ Teaching Hospital Batticaloa, Sri Lanka
}

Keywords: Colonoscopy; exploratory laparotomy;
splenectomy

\section{Introduction}

Colonoscopy is a procedure used as a diagnostic and therapeutic modality of colonic and rectal pathologies. Although colonoscopy is considered a safe procedure, it is associated with complications like intraluminal bleeding and perforation of the colon [1]. Splenic injury during colonoscopy is a rare and life-threatening complication.

\section{Case presentation}

A 63 years old male presented with generalized abdominal pain and distention for two hours duration in the evening. On that same day morning, he underwent colonoscopy for constipation and per rectal bleeding for six years. He was discharged in the evening and readmitted. The colonoscopy finding was diverticulosis noted at descending colon with distended descending and sigmoid colon. He was discharged with syr. Lactulose and dietary advice.

He was a known patient with chronic obstructive pulmonary disease, hypertension and cerebrovascular accident, and was on Aspirin. He underwent cataract surgery in the past. He was allergic to penicillin and some foods. On examination, he was dyspnoeic and afebrile. The abdomen was not significantly distended, but there was generalized tenderness with guarding. His pulse rate was $90 \mathrm{bpm}$, blood pressure was $100 / 60 \mathrm{mmHg}$ and oxygen saturation was $90 \%$ on pulse oximetry. Urgent ultrasound scan of the abdomen showed the moderate amount of free fluid in the abdominal cavity but erect chest Xray showed no gas under the diaphragm. Laboratory results were as follows: leukocyte count: $22.68 \mathrm{x}$ $103 / \mu \mathrm{L}$, haemoglobin: $9.6 \mathrm{mg} / \mathrm{dL}$ and platelet: $225 \mathrm{x} 103 / \mu \mathrm{L}$.

He underwent exploratory laparotomy under general anaesthesia. There was hemoperitoneum with $1700 \mathrm{ml}$ of blood with clots and capsular tear of the spleen with bleeding was noted. Bruising along the ascending and descending

Correspondence: N.Paheerathan

E-mail: nnpahee@gmail.com

(iD https://orcid.org/0000-0001-5383-7101

Received: 04-09-2019 Accepted: 28-08-2020

DOI: http://doi.org/10.4038/sljs.v38i2.8592

The Sri Lanka Journal of Surgery 2020; 38(2): 78-79 colon and colonic diverticulosis were seen but no bowel perforation was identified. Splenectomy was done and haemostasis achieved. The patient was received three pints of blood and managed in an intensive care unit and uneventfully discharged.

\section{Discussion}

Splenic injury during colonoscopy is a rare complication with an incidence of $0.00005-0.017 \%$ and a mortality rate of 5\% [1]. Acute abdominal pain following colonoscopy is the most reliable symptom and requires further investigation and monitoring. Intra-abdominal bleeding causes persistent hemodynamic instability which mandates fluid resuscitation and operative intervention. The incidence of splenic injury during colonoscopy will probably high in the upcoming years due to the widespread use of the procedure [2].

The most possible mechanism for splenic injury even in the experienced hands is tension on the splenocolic ligament or pre-existing adhesions and existing splenic pathology may increase the risk [3]. Direct injury to spleen through the perforation of the colon is also possible. Prevention of these complications can be assisted by avoiding loop formation of scope, insufflation, and careful monitoring of a patient's response, especially under sedation during the procedure.

There is a high chance of splenic injury when patients under sedation during colonoscopy because patients cannot complain about pain and discomfort associated with overstretching of the colon and splenocolic ligament [3]. Some technical manoeuvres during colonoscopy may increase the risk of splenic injury such as the external pressure applied on the left hypochondrium, formation of an $\alpha$-loop and straightening of the sigmoid loop [4].

The severity of the injury can be identified by the symptoms and signs at the time of admission. On admission, our patient doesn't have features of shock probably due to arrest of bleeding and the compensatory mechanisms.

Gas under the diaphragm on a plain erect chest X-ray can diagnose a perforation of the colon. Ultrasonography and contrast-enhanced computed tomography are both reliable investigations to diagnose intra-abdominal free fluid. The 
gold standard imaging is contrast-enhanced computed tomography because it can also detect injuries to other organs, and it gives the grading of splenic injuries [5].

Treatment options include observation in a high dependency unit, selective arterial embolization of splenic vessels, or emergency splenectomy; these options depend on the haemodynamic status of the patient, the type of blood loss (venous vs. arterial), and the availability to perform selective arterial embolization. Evidence shows, splenectomy is the treatment of choice for haemodynamically unstable patients and it is the most used option in $56.1 \%[1,5]$ followed by conservative treatment in 27.3\% [1] and embolization in 4.5\% [1]. Conservative treatment with close monitoring is an option for haemodynamically stable patients [2].

\section{Conclusion}

Splenic injury following colonoscopy is a rare complication and can be minimized by various techniques. Suspect splenic injury and other complications when a patient with acute abdominal pain and shock after colonoscopy. According to the current literature, splenectomy for haemodynamically unstable patients while conservative management is a safe option for stable patients.
All authors disclose no conflict of interest. The study was conducted in accordance with the ethical standards of the relevant institutional or national ethics committee and the Helsinki Declaration of 1975, as revised in 2000 .

\section{References}

1. Ha JF, Minchin D: Splenic injury in colonoscopy: a review. Int J Surg 2009; 7:424-427. https://doi.org/10.1016/j.ijsu.2009.07.010

2. Guner A, Kaya U, Kece C, Kucuktulu U: Is non-operative management feasible for splenic injury due to colonoscopy? BMJ Case Rep 2013;2013:bcr2013009286. https://doi.org/10.1136/bcr-2013-009286

3. Pfefferkorn U, Hamel CT, Viehl CT, et al: Haemorrhagic shock caused by splenic rupture following routine colonoscopy. Int J Colorectal Dis 2007;22:559-560. https://doi.org/10.1007/s00384-005-0750-5

4. Shatz DV, Divas LA, Doherty JC: Management options of colonoscopic splenic injury. JSLS 2006;10:239-243.

5. Hildebrand DR, Ben-Sassi A, Ross NP, Macvicar R, Frizelle FA, Watson AJ: Modern management of splenic trauma. BMJ 2014;348:g1864. https://doi.org/10.1136/bmj.g1864

\section{Learning Points:}

- Splenic injury without colonic perforation following colonoscopy is a rare complication.

- Acute abdominal pain with haemodymanic instability following colonoscopy requires further investigation.

- Contrast enhanced computed tomography is the gold standard radiological examination.

- Splenectomy is the treatment of choice for haemodynamically unstable patients. 